\title{
Study on Steroid Utilization Pattern in a Tertiary Care Teaching Hospital
}

\author{
Arjan Aryal ${ }^{1 *}$, Keshav Kunwar ${ }^{1}$, Sepideh Shadvar ${ }^{1}$, Sanju Kharel', Rajeswari Ramasamy ${ }^{2}$, \\ Gopalakrishna Shashidhar ${ }^{3}$, Samayam Aneesh ${ }^{4}$, Teena Nazeem ${ }^{5}$
}

${ }^{1}$ Pharm.D Intern, Department of Pharmacy Practice, Krupanidhi College of Pharmacy, Bangalore, Karnataka, INDIA

${ }^{2}$ Associate Professor, Department of Pharmacy Practice, Krupanidhi College of Pharmacy, Bangalore, Karnataka, INDIA

${ }^{3}$ Department of General Medicine, MVJ Medical College and Research Hospital, Bangalore, Karnataka, INDIA

${ }^{4}$ Department of Dermatology, MVJ Medical College and Research Hospital, Bangalore, Karnataka, INDIA

${ }^{5}$ Department of Pharmacy Practice, Krupanidhi College of Pharmacy, Bangalore, Karnataka, INDIA

\begin{abstract}
Background: Rational use of corticosteroids is very essential for improving patient safety on long term use. AIM: To study the prescribing pattern of steroids in teaching hospital. Method: A prospective observational study was conducted in the department of dermatology and general medicine in a tertiary care teaching hospital for the period of 6 months. All patients receiving any category of Steroid therapy were included and the prescribing and tapering pattern of steroids were reviewed. Result: Prescribing pattern was observed and analysed in 226 participants during the study period. Steroids were prescribed for various Respiratory illnesses $(59.32 \%)$ and Skin related conditions $(33.18 \%)$. The steroid utilization was found to be more in elderly patients, particularly males. Inhaler administration was common in $44.5 \%$ of cases. Budesonide was the most commonly prescribed $(43.45 \%)$ followed by Prednisolone (15.25\%) and Hydrocortisone (14.91\%). Budesonide + Hydrocortisone were the most common therapy given in combination (35.19\%). In topical preparation, Ultra potent Steroid Clobetasol (45.93\%) was commonly prescribed and in Systemic Preparation, Intermediate acting steroid Prednisolone (37.82\%) was used. Most drugs were prescribed rationally although some factors like improper history, drug administration time and tapering were deviating away from rationality. Conclusion: Not much variation was found in the pattern of prescription amongst the healthcare professionals. Although most of the drugs were prescribed rationally, involvement of a Clinical pharmacist in patient care can help in more rational prescribing along with prevention and early detection of ADRs which can directly promote drug safety and better patient outcomes.
\end{abstract}

Key words: Prescribing pattern, Rationality, Tapering, Steroids, General Medicine, Dermatology.

\section{INTRODUCTION}

Corticosteroids are of great value in treating a wide spectrum of inflammatory conditions as they provide rapid symptomatic relief, especially in the short term. These highly efficacious drugs are mostly used for the treatment or various autoimmune, respiratory and dermatological conditions. ${ }^{1}$ However, these may show harmful effects when used for a longer duration of time. ${ }^{2}$ The dose of corticosteroids that is prescribed, dispensed and applied must be carefully considered as too little steroid can show poor response whereas excess application can increase the risk of adverse reac- tion. ${ }^{3}$ For this, rational use is necessary to minimize both systemic and cutaneous side effects. ${ }^{4}$

In India, most of these medications, especially topical corticosteroids are sold without any prescription or patient can easily obtain these medications from local pharmacy. As per the information available on the Central Drugs Standard Control Organization (CDSCO) website, it's off label use is more commonly practised in India.-6 Also, it's inappropriate use in the treatment of various dermatological disorders like acne, bacterial or fungal infections, and rash
DOI: 10.5530/ijopp.10.2.19

Address for correspondence:

Arjan Aryal,

Pharm.D, Krupanidhi College of Pharmacy, \#12/1, Chikkabellandur, Carmelaram Post, Varthur, Hobli, Bangalore, Karnataka, INDIA.

Phone no: 8105433709

E-mail: mynameisarjan@gmail. com

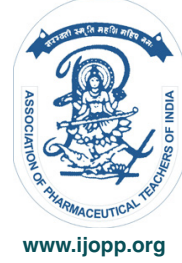


by non-registered practitioners or on the advice of pharmacist or chemist shops is a major concern..$^{7-8}$ This will increase the adverse effects and can lead to dependence on these medications. So, urgent steps are required to eliminate the root of this problem at the earliest. Periodic monitoring of the drug utilization pattern is one of the methods to analyse the rationality of the drug and has been an effective tool to constitute guidelines for improving the utilization pattern. ${ }^{9}$ This will not only constitute a rational therapy but also lead to economic benefit and easy identification of the problem related to drug use like Poly pharmacy, drug interactions and adverse reactions. ${ }^{10}$

The main aim of the study is to analyse the prescribing pattern of corticosteroids among the patients from general medicine and dermatology department of MVJ medical college and research hospital located in Bangalore, South India. The significance of the study is to improve the patient safety on long term use of steroid therapy by observing the prescribing pattern as irrational use of steroids can increase the risk of adverse effects. Moreover, the lack of medical education from the health care professionals to the patients enforces the conduction of the study.

\section{METHODOLOGY}

\section{Study Design}

This prospective, observational study was conducted for 6 months from October 2015 to March 2016 in accordance with the ethical principles of declaration of Helsinki and principles of current Good Clinical Practice (GCP). The study protocol was approved by the Institutional Review Board (IRB) with ethical clearance number: Central Research/MVJ MC\& RH/08/2016.

\section{Study Site}

Department of General Medicine and Department of Dermatology, MVJ Medical College and Research Hospital, Bangalore, South India.

\section{Inclusion criteria}

All the patients of various age groups who received any category of steroid therapy in both the departments were included. The patients who presented a past history of steroid intake and those who have been reported of abusing steroids were also included.

\section{Exclusion Criteria}

Patients who met all the inclusion criteria but not willing to participate in the study were excluded.

\section{Operational Definitions}

The following are the operational definition of some important terms defined by the investigators for the study purpose.

Steroid Abuse: was defined as inappropriate use of steroids for a period of more than one year.

Rationality: Rationality was defined as the prescribing the right drug in adequate dose for sufficient duration and appropriate to the clinical needs of the patient. The rationality of the drug was determined using several factors which were prescriber related factors, administration related factors and proper dose tapering.

Prescriber related factors: was defined as those factors which influenced the rational prescribing of steroids through the prescribers such as Taking accurate medical and medication history, using generic name of the drug, mentioning dose, mentioning frequency of administration, direction for topical application $\&$ legibility of medication orders.

Administrator related factors: was defined as those factors influencing the rational use of steroids through the administrator (nurse or any care taker including the patient itself) that includes Dose omission (Missing to administer the dose), wrong (delayed or early) administration time, improper documentation (drug administered but not documented)

Tapering: was defined as appropriate gradual dose reduction in appropriate intervals with patient monitoring.

\section{Method}

All the patients who met the inclusion criteria were enrolled in the study after taking Informed Consent (IC) before commencing the study. The basic demographics, medication related details and laboratory investigation values were collected by the researchers personally using the case report form. The prescribing pattern of the steroids in both the departments was reviewed with a special emphasis on rationality and proper tapering of the steroids. The various factors affecting the rational use of steroids by prescribers were measured by understanding the complete medical and medication history of enrolled cases, and by reviewing the medication chart.

Similarly, the administration related factors were measured by checking the nurse's sheet and asking the patients or care takers about administration route and time. If doubtful, the same was discussed with the nurse as well as the doctors. The tapering of various steroids were analysed using steroid tapering guidelines through literatures available. Finally, 
the results were analysed using descriptive statistical methods and were reported to concerned departments.

\section{RESULTS}

\section{Basic demographic data}

A total of 226 patients were enrolled out of which 62 patients were from dermatology department and 164 patients were from general medicine department. Majority of the study subjects who participated in this study were belonging to the age group of $>61$ years followed by 51-60 years of age and 31-40 years. Similarly, more number of males was found to be using corticosteroids as compared to females. Likewise, significant number of patients was found to be smokers and majority of the patients were found to be illiterate. The detailed demographic data is demonstrated in Table 1.

\section{System associated with steroids use}

Out of 226 cases, patients with different systems such as Respiratory, CVS, Skin, Blood vessels, Neurological and skeletal systems were enrolled. Various skin diseases were recorded. Out of 71 dermatological disorders, Papulogranulous. Disorder patients weremaximum. Patients with cutaneous Neoplasm, eczema, Autoimmune disorder, fungal infection, collagen disorder, drug reactions and others dermatological disorders were present. The different system associated with steroid use is demonstrated in Table 2 and the various skin diseases associated with steroid use is demonstrated in Table 3.

*LRTI: Lower pulmonary tract infection, COPD: Chronic obstructive pulmonary disease, OSD:

\begin{tabular}{cc}
$\begin{array}{c}\text { Table 1: Basic Demographic Data (N=226) } \\
\text { Gender }\end{array}$ & Number of Patients (\%) \\
\hline Male & 58.4 \\
Female & 41.6 \\
Age in years & \\
\hline$<20$ & 4.87 \\
$21-30$ & 8.85 \\
$31-40$ & 15 \\
$41-50$ & 11.94 \\
$51-60$ & 22.12 \\
$>60$ & 37.22 \\
Social Habits & \\
\hline Smoker & 38.93 \\
Non smoker & 61.07
\end{tabular}

Ostium Secundum defect, Others: Pneumonia, Pulmonary Koch, Shortness of breath/ Difficulty in breathing.

Table 2: Systems Associated with Steroids use ( $N=226)$.

\begin{tabular}{ccc}
\hline System involved & No of Patients & Percentage (\%) \\
\hline Respiratory & $\mathbf{1 3 5}$ & $\mathbf{5 9 . 3 2}$ \\
\hline 1. LRTI & 33 & \\
2. COPD & 38 & \\
3. Bronchitis & 30 & \\
4. Asthma & 16 & \\
5. Others & 18 & $\mathbf{0 . 4 4}$ \\
CVS (OSD) & $\mathbf{1}$ & $\mathbf{3 3 . 1 8}$ \\
\hline Skin & $\mathbf{7 5}$ & $\mathbf{5 . 3}$ \\
\hline Skeletal & $\mathbf{1 2}$ & \\
\hline 1. Spondylitis & 4 & \\
2. Osteoarthritis & 3 & $\mathbf{0 . 8 8}$ \\
3. Polyarthritis & 5 & \\
Blood Vessels & $\mathbf{2}$ & \\
\hline 1. Vasculitis & 1 & $\mathbf{0 . 8 8}$ \\
2. Thromboembolism & 1 & \\
Neurological & $\mathbf{2}$ & \\
\hline 1. Meningis & & \\
\hline
\end{tabular}

1. Meningitis

Table 3: Dermatological Disorder Associated with Steroid use ( $\mathrm{N}=75)$.

\begin{tabular}{ccc}
\hline Disease & $\begin{array}{c}\text { Total no of } \\
\text { Patient }\end{array}$ & $\begin{array}{c}\text { Percentage } \\
\text { (\%) }\end{array}$ \\
\hline Cutaneous Neoplasm & 2 & 2.66 \\
1. Mycosis Fungoides & 2 & \\
Papulogranulous Disorder & 22 & \\
1. Psoriasis & 18 & 29.33 \\
2. Lichen Planus & 4 & \\
Eczema/ Dermatitis & 12 & 16 \\
Auto-immune & 15 & 20 \\
1. Pemphigus Vulgaris & 6 & \\
2. Lichen Amyloidosis / & 2 & \\
Mucinosis & & \\
3. Vitiligo & 4 & \\
4. Daries Disease & 1 & \\
5. Systemic Sclerosis & 1 & \\
6. Dermatomyositis & 1 & \\
Fungal infection (Tinea & 1 & \\
Incognito) & 1.33 \\
Collagen Disorder (SLE) & 1 & \\
Drug Reaction (Fixed Drug & 3 & \\
Eruption) & 19 & \\
Others & & \\
& & \\
\hline
\end{tabular}




\begin{tabular}{|c|c|c|c|c|c|c|}
\hline \multirow[t]{2}{*}{ Steroids } & \multicolumn{2}{|c|}{$\mathrm{GM}(\mathrm{N}=218)$} & \multicolumn{2}{|c|}{$D(N=81)$} & \multirow[t]{2}{*}{ Total No of Patients } & \multirow[t]{2}{*}{ Percentage $\mathrm{N}=299$} \\
\hline & No & $\%$ & No & $\%$ & & \\
\hline Clobetasol & 0 & 0 & 23 & 29.11 & 23 & 7.79 \\
\hline Dexamethasone & 20 & 9.26 & 8 & 10.12 & 28 & 9.49 \\
\hline Prednisolone & 19 & 8.8 & 26 & 30.42 & 45 & 15.25 \\
\hline Budesonide & 132 & 60.2 & 0 & 0 & 132 & 43.45 \\
\hline Hydrocortisone & 43 & 19.9 & 1 & 1.26 & 44 & 14.91 \\
\hline Mometasone & 2 & 0.92 & 8 & 10.12 & 10 & 3.39 \\
\hline Fluticasone & 1 & 0.46 & 4 & 5.06 & 5 & 1.69 \\
\hline Betamethasone & 0 & 0 & 1 & 1.26 & 1 & 0.33 \\
\hline Desonide & 0 & 0 & 1 & 1.26 & 1 & 0.33 \\
\hline Halobetasol & 0 & 0 & 5 & 6.33 & 5 & 1.69 \\
\hline Triamcinolone & 0 & 0 & 4 & 5.06 & 4 & 1.35 \\
\hline Methyl Prednisolone & 1 & 0.46 & 0 & 0 & 1 & 0.33 \\
\hline
\end{tabular}

* Others: Steven Johnson Syndrome, Leprosy, Pruritis, Delusional Parasitosis, Herpes Zoster, Acne, Urticaria, Bullous Pemphigoid.

\section{Various steroids used}

A total of 299 steroid drugs were prescribed in 226 patients during the study period. Out of 218 drugs in General Medicine ward, Dexamethasone, Prednisolone, Budesonide, Hydrocortisone and Mometasone and Fluticasone were prescribed respectively whereas in Dermatology Department, out of 81 drugs, Clobetasol, Dexamethasone, Prednisolone, Hydrocortisone, Mometasone, Halobetasol and Fluticasone, Betamethasone, Desonide and Methyl Prednisolone were prescribed. The various steroids used in both general medicine and dermatology department is illustrated in Table 4.

\section{Classification of steroids}

The steroid Classification is made based on potency for Topical Steroids and also based on Duration of Action for Systemic Steroids.

\section{Steroid classification based on potency}

Out of 47 Topical Corticosteroids, Ultra High Potency Corticosteroids which Comprised of Clobetasol and Halobetasol were commonly prescribed. High potency corticosteroids like Triamcinolone were prescribed for moderately severe cases whereas Moderate Potency Corticosteroids comprising of Mometasoneand Fluticasone were prescribed for moderate severity cases. Low Potency Corticosteroid like Desonide was prescribed for mild cases as shown in Table 5.

\section{Steroid classification based on duration of action}

Out of 119 glucocorticoids prescribed Short Acting Corticosteroid that comprised of Hydrocortisone, Intermediate Acting Corticosteroid that comprised of Prednisolone and Methyl Prednisolone was commonly prescribed. Long Acting Corticosteroid that comprised of Dexamethasone and Betamethasone were prescribed for conditions that required longer duration of action which is shown in Table 6.

\section{Route of administration}

\begin{tabular}{|c|c|c|c|}
\hline Classification & Drug & $\begin{array}{c}\text { Number } \\
(\%)\end{array}$ & $\begin{array}{c}\text { Percentage } \\
(\%)\end{array}$ \\
\hline \multirow{2}{*}{$\begin{array}{l}\text { Ultra High } \\
\text { Potency }\end{array}$} & Clobetasol & $23(48.93)$ & 59.56 \\
\hline & Halobetasol & $5(10.63)$ & \\
\hline High Potency & Triamcinolone & 4 & 8.51 \\
\hline \multirow[t]{2}{*}{ Moderate Potency } & Mometasone & $10(21.27)$ & 29.8 \\
\hline & Fluticasone & $4(8.51)$ & \\
\hline Low Potency & Desonide & 1 & 2.13 \\
\hline
\end{tabular}

Table 6: Steroid Classification based on Duration of Action ( $n=119)$.

\begin{tabular}{cccc} 
Classification & Drug & $\begin{array}{c}\text { Total } \\
\text { Number }\end{array}$ & $\begin{array}{c}\text { Percentage } \\
\text { (\%) }\end{array}$ \\
\hline Short Acting & Hydrocortisone & 44 & 36.97 \\
Intermediate & Prednisolone & 45 & 37.82 \\
Acting & Methyl Prednisolone & 1 & 0.84 \\
Long Acting & Dexamethasone & 28 & 23.53 \\
& Betamethasone & 1 & 0.84
\end{tabular}


Out of 299 drugs, Topical administration were found to be for 47 cases, Oral administration were also prescribed for 47 cases, Drugs administered though injection (Intravenously) were found to be for 72 cases and 133 cases were found to have administered with Inhalers as illustrated in Figure 1.

\section{Rationality}

The rationality of steroids is measured on the basis of Prescriber related factors, Administration related factors, Steroid Abuse and Dose Tapering.

\section{Prescriber related factors}

Out of 299 drugs, very few drugs were prescribed in generic name. Frequency and dose was mentioned

\begin{tabular}{lrrrrr}
\hline $\begin{array}{l}\text { Table 7: Prescriber Related Factors } \\
\text { (N=299). }\end{array}$ \\
$\begin{array}{c}\text { Prescriber Related } \\
\text { Factors }\end{array}$ & \multicolumn{2}{c}{$\begin{array}{c}\text { Total Drugs } \\
\text { (N=299) }\end{array}$} & \multicolumn{2}{c}{ Percentage } \\
\hline & Yes & No & Yes (\%) & No (\%) \\
Generic Name Used & 69 & 230 & 23.07 & 76.93 \\
$\quad \begin{array}{l}\text { Frequency } \\
\text { Mentioned }\end{array}$ & 278 & 21 & 92.97 & 7.03 \\
Dose mentioned & 260 & 39 & 86.95 & 13.05
\end{tabular}

\begin{tabular}{ccccc}
\hline $\begin{array}{c}\text { Table 8: Prescriber Related Factors (N=226). } \\
\text { Prescriber Related } \\
\text { Factors }\end{array}$ & $\begin{array}{c}\text { Total Cases } \\
\text { (N=226) }\end{array}$ & \multicolumn{2}{c|}{ Percentage (\%) } \\
\hline $\begin{array}{c}\text { Yes } \\
\text { Inaccurate History }\end{array}$ & 81 & 145 & 35.84 & 64.16 \\
$\begin{array}{c}\text { Taken } \\
\text { Illegible Handwriting }\end{array}$ & 86 & 140 & 38.05 & 61.95 \\
\hline
\end{tabular}

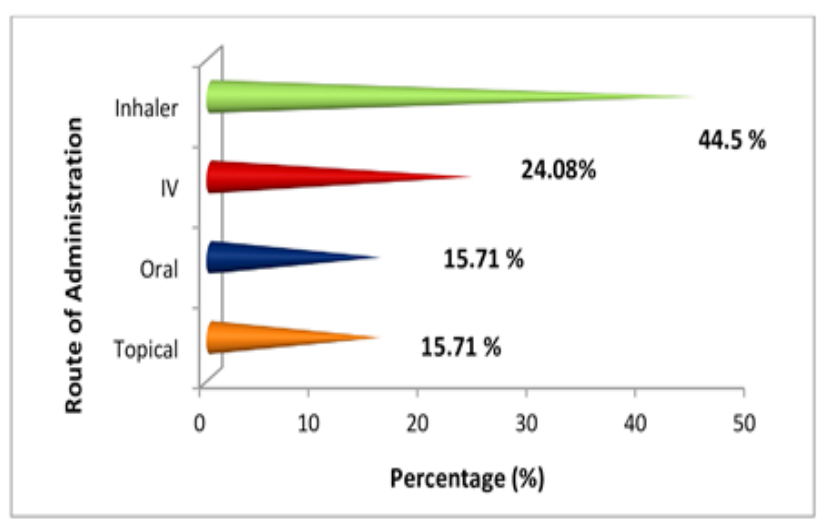

Figure 1: Route of Administration. for most of the drugs which are shown in Table 7. Similarly, Out of 226 cases, inaccurate history was taken for few cases and few cases were found to have illegible handwriting which is shown in Table 8.

\section{Administration related factors}

Out of 226 Cases, Improper Recording was done for very few cases and Dose Omission and wrong administration time was were present for negligible cases as shown in Table 9.

\section{Dose tapering}

Out of 119 drugs, which need tapering, most of them were tapered and few of them were not tapered as shown in Figure 2.

\section{Table 9: Administration Related Factors ( $\mathrm{N}=226$ ).}

\begin{tabular}{lll}
\multicolumn{1}{c}{$\begin{array}{c}\text { Administrative Related } \\
\text { Factors }\end{array}$} & \multicolumn{1}{c}{$\begin{array}{c}\text { Total } \\
\text { Cases }\end{array}$} & \multicolumn{1}{c}{$\begin{array}{c}\text { Percentage } \\
\text { (\%) }\end{array}$} \\
\hline Improper Recording & 54 & 23.89 \\
Wrong Administration Time & 16 & 7.07 \\
Dose Omission & 6 & 2.65
\end{tabular}

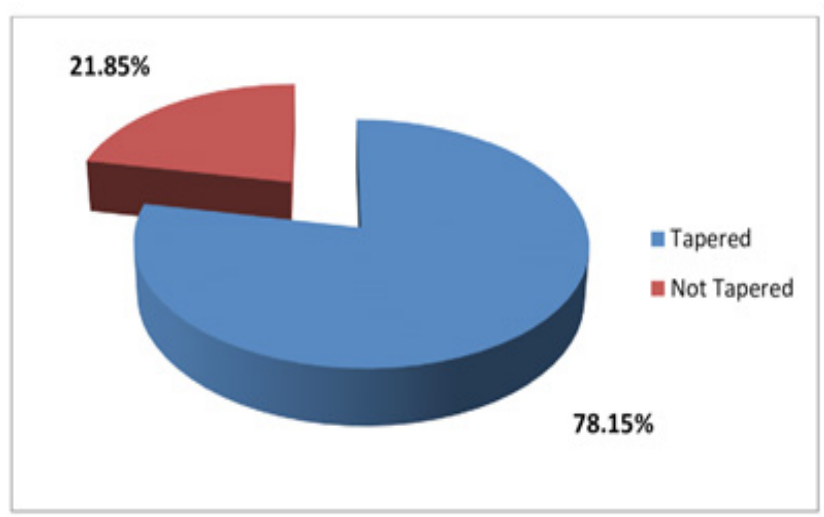

Figure 2: Dose Tapering.

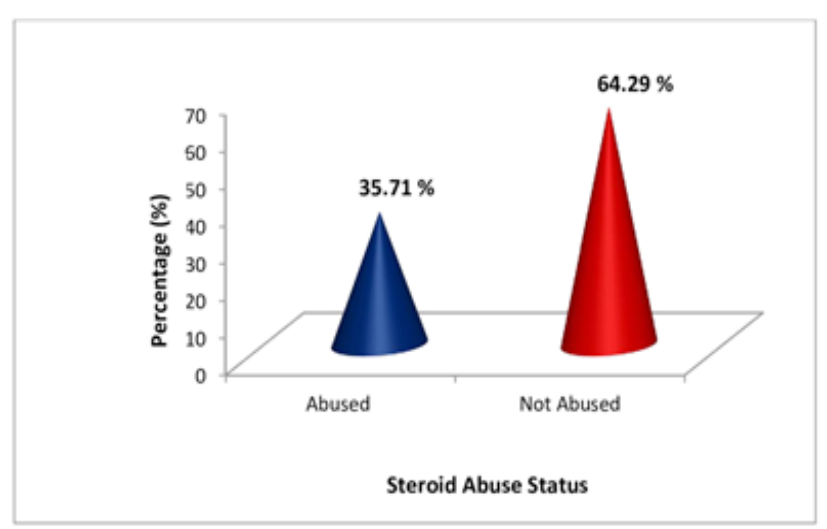

Figure 3: Steroid Abuse Status.

Indian Journal of Pharmacy Practice, Vol 10, Issue 2, Apr-Jun, 2017 


\section{Steroid abuse status}

Out of 226 patients, 42 patients were found to have a past medication history of steroids. Out of 42 patients, 15 patients were found abusing steroids and 27 were not abusing steroids which is shown in Figure 3.

\section{DISCUSSION}

Corticosteroids are commonly used for the treatment of many inflammatory and autoimmune conditions which makes time to time reviewing of the prescription and rational prescribing of the drugs is essential to increase the therapeutic efficacy and decrease the adverse effects of the drugs.

Two hundred twenty six patients were enrolled in the study where $27.5 \%$ were enrolled from the department of dermatology and $72.5 \%$ were enrolled from the Department of General Medicines. Male patients were $58.4 \%$ and $41.6 \%$ were female respectively. In our study, majority of corticosteroid received patients belonged to age group $>60$ years followed by age group of $51-60$ years. This is supported by study conducted in United Kingdom by L $\mathrm{J}$ Walsh et al. ${ }^{11}$ Likewise; the social status of our study reported smokers $38.93 \%$ and non-smokers $61.07 \%$. This is supported by a study conducted by Dennis Chen et al carried out in south Texas who reported $47.7 \%$ of their patients to be smokers. ${ }^{12}$

The major clinical complaints of the patients admitted in general medicine were related to Respiratory Tract $(59.32 \%)$ followed by Dermatological complaints (33.18\%), Skeletal (5\%), Blood Vessel $(0.88 \%)$ and Neurological $(0.88 \%)$ which was similar to study done by SanojVarkey et al in pulmonary department, ${ }^{13}$ TP VanStaa et al who conducted the study in general medicine department ${ }^{14}$ and a study done in Maharashtra by Wahane Pravin kumar et al who conducted the study in dermatology department. ${ }^{15}$ Non-infectious skin diseases like psoriasis topped the Table by $29.33 \%$, followed by Eczema (16\%), Pemphigus Vulgaris (8\%). Infectious disease like fungal infection topped the Table (8\%). This disease pattern is comparable to the study conducted by CM Divysanthi et al in Karaikal ${ }^{16}$ which showed similar reports. This shows that the incidence of the skin disease depends mostly on geographical location, genetic makeup as well as environmental factors.

Majority of patients were prescribed with ultra-high potent class of corticosteroids (59.56\%) i.e Clobetasol (48.93\%) and Halobetasol (10.63\%) in Dermatology department. In spite of the fact that these can cause serious adverse effects, these are easily available and are sold without prescription and also there is very little awareness about the potential side effects in the general public. The most widely prescribed corticosteroids were Budesonide (44.45\%), followed by Prednisolone (15.25\%), Hydrocortisone $(14.9 \%)$, Dexamethasone $(9.49 \%)$ in General Medicine department whereas Desonide $(0.33 \%)$, Fluticasone (0.33\%), Methyl Prednisolone (0.33\%) were found to be least in both departments. As far as the indication being concerned, topical Clobetasol was the most prescribed drug for psoriasis. This study is comparable to the two studies carried out by PK Thakur et al ${ }^{17}$ and SP Narwane et al. ${ }^{18}$

Inhaler administration was found to be highest (44.5\%) followed by drugs administered through intravenously $(24.08 \%)$, Oral administration and topical were found to be lowest (15.71\%). These all data suggested that among various dosage forms of steroids use, nebulisation was most widely/ frequently used followed by injection, Table ts and topical. This data is supported by Kumar MA et al study carried out in Tamil Nadu. ${ }^{9}$ We also found out that corticosteroids were never prescribed in any route to treat infectious skin diseases which signifies that the rational prescription is sincerely followed.

It was found out that right steroids were prescribed for right indication to right patients. This assures that rationality is genuinely followed while prescribing. However we found some factors deviating from rationality like inappropriate drug history, Drug dose not mentioned, frequency not mentioned, wrong administration, dose omission, illegible hand writing, lack of dose tapering and steroid abuse. Not specifying these factors can lead to under usage of the medication and can lead to sub therapeutic outcome and at the same time excessive usage can lead to unwanted effects., ${ }^{3,10}$ Few patients were found to be abusing steroids due to lack of knowledge towards medication. Clear instructions should be provided so that the patients are aware on how much steroid should be used and how long it should be used. ${ }^{19}$ Also, Generic name for most of the drugs were not mentioned at all. Using generic names usually provides flexibility to the dispensing pharmacist and generic drugs are less expensive than the branded drugs. ${ }^{20}$

Most of the drugs were prescribed for right indication to right patient, however some factors such as in appropriate drug history, improper mentioning of dose \& frequency, wrong administration time, dose omission, improper dose tapering etc. were found to be deviating away from the rationality. The use of 
steroids is seen more in elderly patients that suggest that elderly patients should be monitored closely while treating them with Steroids.

\section{Limitations}

Potential limitation of this study was the limited sample due to short study period. The data were collected only from October 2015 to March 2016. Another limitation of our study was restriction only to In- Patient Department of General medicine and dermatology practice. Very few patients were available in Dermatology department as most of the patient did not require hospital admission. Regional language barrier during communication with patients when supporting staff not available in the ward was another limitation.

\section{Future outlook}

Easy availability of the steroids in pharmacies, especially topical steroids is one of the major factors responsible for irrational use. Irrational use /Abuse of topical or systemic steroids may lead to severe ADRs and affects the quality of life of patients. Hence, establishing standard guidelines for prescribers for treating any acute and chronic diseases where steroids necessary is highly warranted. Creating awareness on appropriate use of steroids amongst public can be encouraged. Also, there is an increasing need to strengthen the laws regarding the procurement, storing, dispensing of steroidal medicines at the retail pharmacies. Future research should also focus on organising workshops for pharmacists on a regular interval basis in order to update and improve their knowledge on safe and rational use of these drugs, as pharmacists play an important role in counselling the patients on this behalf.

\section{CONCLUSION}

There was not much variation found in the pattern of prescription amongst the healthcare professionals. Although most of the drugs were prescribed rationally, involvement of a Clinical pharmacist in patient care can help in rational prescribing as well as prevention of ADRs. The pharmacist can promote drug safety and better patient care, among health care professionals. Establishment of standardized approaches for steroid usage for various indications is highly warranted for Indian set up. Active reporting of suspected.

ADR's by all healthcare professionals including, clinical pharmacists, Nurses and Practicing clini- cians will improve the safe use of drugs and better patient outcome.

\section{ACKNOWLEDGEMENT}

The authors extend their gratitude towards principal of Krupanidhi College of Pharmacy and MVJ medical college and research hospital for providing necessary facilities to carry out the research work. The authors are also thankful to the entire nursing staff from both general medicine and dermatology department for their services.

\section{CONFLICT OF INTEREST}

The authors declare no conflict of interest.

\section{ABBREVIATION USED}

ACTH: Adrenocorticotrophic Hormone; ADR: Adverse Drug Reaction; CDSCO: Central Drugs Standard Control Organization; CRF: Case Report Form; CVS: Cardiovascular System; GCP: Good Clinical Practice; ICF: Informed Consent Form; IRB: Institutional Review Board.

\section{REFERENCES}

1. Hengge UR, Ruzicka T, Schwartz RA, Cork MJ. Adverse effects of topical glucocorticosteroids. Journal of the American Academy of Dermatology. 2006;54(1):1-5. https://doi.org/10.1016/j.jaad.2005.01.010; PMid:16384751.

2. Schoepe S, Schäcke H, May E, Asadullah K. Glucocorticoid therapy-induced skin atrophy. Experimental dermatology. 2006;15(6):406-20. https://doi. org/10.1111/j.0906-6705.2006.00435.x; PMid:16689857.

3. Ference JD, Last AR. Choosing topical corticosteroids. American family physician. 2009;79(2). PMid:19178066.

4. Sharma SC, Uppal R, Sharma PL, Kaur S. Rational use of topical corticosteroids in dermatology. Indian Journal of Pharmacology. 1990;22(3):141.

5. Fixed Dose Combinations approved By DCG (I) since 1961 till July, 2014. Central Drugs Standard Control Organization, India.

6. Approval Status of New Drug during 1971-1998. Central Drugs Standard Control Organization, India. Available from: http://cdsco.nic.in/ writereaddata/1971-98. doc. [Last accessed on 2016 Dec 25].

7. Saraswat A, Lahiri K, Chatterjee M, Barua S, Coondoo A, Mittal A, et al. Topical corticosteroid abuse on the face: A prospective, multicenter study of dermatology outpatients.

8. Ambika H, Vinod CS, Yadalla H, Nithya R, Babu AR. Topical corticosteroid abuse on the face: A prospective, study on outpatients of dermatology. Our Dermatol Online. 2014;5:5-8. https://doi.org/10.7241/ourd.20141.01.

9. Kumar AM, Noushad PP, Shailaja K, Jayasutha J, Ramasamy C. A study on drug prescribing pattern and use of corticosteroids in dermatological conditions at a tertiary care teaching hospital. Int j pharm sci rev res. 2011;9:132-5.

10. Sweileh WM. Audit prescribing practices of topical corticosteroids in outpatient dermatology clinics in northern Palestine. Eastern Mediterranean Health Journal. 2006;12(1-2):161-9. PMid:17037234.

11. Walsh LJ, Wong CA, Pringle M, Tattersfield AE. Use of oral corticosteroids in the community and the prevention of secondary osteoporosis: a cross sectional study. Bmj. 1996;313(7053):344-6. https://doi.org/10.1136/bmj.313.7053.344; PMid:8760745 PMCid:PMC2351752.

12. Chen D, Restrepo M, Fine M, V. Pugh M, Anzueto A, Metersky M et al. Observational Study of Inhaled Corticosteroids on Outcomes for COPD Patients 
withPneumonia. Am J RespirCrit Care Med. 2011;184(3):312-6. https://doi. org/10.1164/rccm.201012-20700C; PMid:21512168 PMCid:PMC3175534.

13. Varkey S, Sen S. Prescribing patterns of corticosteroids in pulmonology department. International Journal of Pharmacy Teaching \& Practices. 2012;3(3):334-7.

14. Van Staa TP, Leufkens HG, Abenhaim L, Zhang B, Cooper C. Use of oral corticosteroids and risk of fractures. Journal of Bone and Mineral Research. 2000;15(6):993-1000. https://doi.org/10.1359/jbmr.2000.15.6.993; PMid:10841167.

15. Wahane PA, Jagtap RP, Ghongane BB. Evaluation of corticosteroid use pattern in steroid responsive dermatological conditions. International Journal of Medical Research \& Health Sciences. 2016;5(1):82-6. https://doi.org/10.5958/23195886.2016.00017.5.

16. Divyashanthi CM, Nandhini A, Kumar SA. Study on drug utilization pattern of antibiotics among dermatology in-patients of a tertiary care teaching hospital, Karaikal, Puducherry.
17. Thakur PK, Majid A, Shramik M, Kumar S. Prospective Study on Drug Utilization Evaluation of Corticosteroids among Out-Patients of Teaching Hospital. InternationalJournal of Pharmacy Teaching \& Practices 2015;6(4): 2630-4.

18. Narwane SP, Patel TC, Shetty YC, Chikhalkar SB. Drug utilisation and cost analysis for common skin diseases in dermatology OPD of an Indian tertiary care hospital- a prescription survey. British Journal of Pharmaceutical Research. 2011;1(1):9-18. https://doi.org/10.9734/BJPR/2011/223.

19. The National Prescribing Centre. Using topical corticosteroids in general practice. MeReC Bulletin 1999;10(6):21-4.

20. Oshikoya KA, Bello JA, Ayorinde EO. Prescribing knowledge and skills of final year medical students in Nigeria. Indian journal of pharmacology. 2008;40(6):251. https://doi.org/10.4103/0253-7613.45150; PMid:21279180 PMCid:PMC3025141. 